\title{
Assessing the usefulness of the outer-area method in quantifying the structural capacity of full-scale composite pavement sections subjected to accelerated pavement testing
}

\author{
A. Francois, D. Offenbacker \& Y. Mehta \\ Center for Research and Education in Advanced Transportation Engineering Systems, Department of Civil \\ Engineering, Rowan University, Glassboro, New Jersey, USA
}

\begin{abstract}
The focus of this study was to evaluate the overall accuracy of the Outer-Area method in quantifying the structural capacity of full-scale, composite pavement sections that are subjected to APT. Five $9.1 \mathrm{~m}$. long and $3.7 \mathrm{~m}$ wide composite field sections were evaluated in this study. All sections contained a similar substructure (i.e., $203 \mathrm{~mm}$, Portland cement concrete base, $406 \mathrm{~mm}$ New Jersey I-3 (A-1-a) granular subbase, and $304 \mathrm{~mm}$, compacted subgrade). Section 1 contained a stone matrix asphalt (12.5-SMA) overlay while Section 2 contained a $50.8 \mathrm{~mm}$ thick, New Jersey high performance thin overlay (NJHPTO) overlay. Sections 3, 4 and 5 contained an overlay that was a combination of a $25 \mathrm{~mm}$ thick, binder rich intermediate course (BRIC) and a $50 \mathrm{~mm}$ layer of a Superpave mixture (9.5-ME), SMA, and NJHPTO, respectively. All sections were instrumented with two asphalt strain gauges and subjected to accelerated pavement testing (APT) using a heavy vehicle simulator (HVS). During APT, a $60 \mathrm{kN}$, dual tire, single axle load was applied to the sections at $8 \mathrm{~km} / \mathrm{h}$ for 200,000 repetitions. Heavy weight deflectometer (HWD) testing was performed on each test section before and after APT. The collected pavement deflection data from each composite section was analyzed using the outer-Area method to determine the overall structural capacity of the bound pavement layers before and after APT. The actual field performance of the test sections was assessed using the strain data collected during APT. Based on the results of the study it was determined that the Outer-Area method may not be able to accurately quantify the damage full-scale composite pavements experience due to APT.
\end{abstract}

Keywords: Guidelines, abstract, title, text, figures

\section{INTRODUCTION}

Heavy weight deflectometer (HWD) testing is a nondestructive method of pavement testing that simulates the deflection of a pavement surface under the action of fast moving traffic load. It is generally used to determine the structural conditions of pavement layers over time. HWD testing involves the application of variable loads on the surface of a pavement via a spring loaded plate. The deformation of the pavement due to the applied loads causes a deflection basin to form within the pavement structure. The pavement response to the applied impulse load is measured by velocity transducers or geophones which, are placed at specific radial distances from the center of the applied load. The measured deflections are then used to compute the estimated layer stiffness through an ill-posed, iterative process referred to as back-calculation (Mehta and Roque 2003). Computer programs are usually used to 
perform back-calculation of multi-layered systems. These computer programs allow users to input estimated initial or "seed" moduli values for the various layers of a pavement. A subroutine program within the back-calculation software then utilizes finite element or multi-layer analyses to determine an "effective" layer moduli which adjusts for stresssensitivity and discontinuities (Maestas and Mamlouk 1992).

Most back-calculation software are capable of computing "effective" layer moduli for flexible and rigid pavement systems. However, these software are limited in their ability to analyze HWD data from composite pavement systems: particularly when the pavement system contains thin HMA overlays. As such transportation agencies have developed procedures to forward calculate the apparent stiffness of the uppermost bound layer(s), of pavement systems under an applied surface load. One such procedure is the Outer Area method that was developed by the Federal highway Administration.

\section{GOAL}

The goal of this study was to evaluate the efficacy of the Outer-Area method in quantifying the structural capacity of full-scale, composite pavement sections that are subjected to APT. In order to accomplish this goal, heavy weight deflectometer testing was conducted on five full-scale, composite pavement sections. The full-scale sections were also subjected to accelerated pavement testing using a heavy vehicle simulator. The HWD data was analyzed using the Outer-Area procedure. The effectiveness of the Outer-Area method in ranking the reduction in structural capacity of the test sections was evaluated by reconciling the analyzed HWD results with the actual damage that occurred in the test sections during to APT.

\section{FIELD SECTION DESCRIPTION AND INSTRUMENTATION}

Five full-scale, pavement sections were evaluated in this study. These pavement sections were located at Rowan University Accelerated Pavement Testing Facility (RUAPTF). The pavement sections were $9.2 \mathrm{~m}$ long by $3.6 \mathrm{~m}$ wide. Figure 1 presents a representative pavement structure (i.e., layers) for all five test sections. All sections had the same supporting layers or substructure (i.e., a Portland cement concrete (PCC) base, a granular aggregate subbase, and compacted natural soil as a subgrade). However, different hot mix asphalt (HMA) overlays were utilized on each test section. Section 1, contained a $76.2 \mathrm{~mm}$ thick, stone matrix asphalt (SMA) overlay, and section 2 contained a $50.8 \mathrm{~mm}$ thick, New Jersey High Performance Thin Overlay (NJHPTO). The overlays on sections 3, 4 and, 5 consisted of a $50.8 \mathrm{~mm}$ thick, Superpave mixture (9.5-ME), $50.8 \mathrm{~mm}$ thick, SMA mixture, and $50.8 \mathrm{~mm}$ thick, 4.75 -HPTO mixture, respectively placed on top of a $25.4 \mathrm{~mm}$ thick, Binder Rich Intermediate Course (BRIC).

Each test section was instrumented with two H-type strain gauges that were placed $12.7 \mathrm{~mm}$ from the bottom of the asphalt overlay. The strain gauges were placed approximately $457 \mathrm{~mm}$ apart, at the joint, between the approach and leaving PCC slabs (Figure 2). One of the strain gauges was placed directly beneath the wheel path of one of the loading tires (dual-tire configuration) while the other was placed at the edge of the loading path.

\section{TESTING AND EVALUATION PLAN}

\subsection{Heavy weight deflectometer testing}

Heavy weight deflectometer testing was performed immediately before and after HVS testing on each test section. The HWD test locations on each full-scale section evaluated in this study is shown in Figure 2. There were six HWD test locations on each test section. Two of these test locations were evaluated in the direction of HVS loading (i.e., TS-1 and TS-2) while the remaining four test locations were evaluated in the opposing direction. The HWD test points 
were located in two zones on each section as shown in Figure 2. HWD Test Zone 1 consisted of the region loaded by the HVS test wheel while Test Zone 2 consisted of the area outside the HVS loading area. HWD testing was performed in these two specific regions of the test sections in order to evaluate the effect of applied HVS loading on pavement section deterioration. The arrows shown in Figure 2 indicate the position of the geophones used to measure pavement deflections. At each test location on the sections, four drop heights that corresponded to target loads of $29.4 \mathrm{kN}, 41.2 \mathrm{kN}, 58.8 \mathrm{kN}$, and $78.4 \mathrm{kN}$, respectively were utilized. Geophones were spaced at 0, $200 \mathrm{~mm}, 300 \mathrm{~mm}, 450 \mathrm{~mm}, 600 \mathrm{~mm}, 900 \mathrm{~mm}$, and $1200 \mathrm{~mm}$, respectively from the applied load.

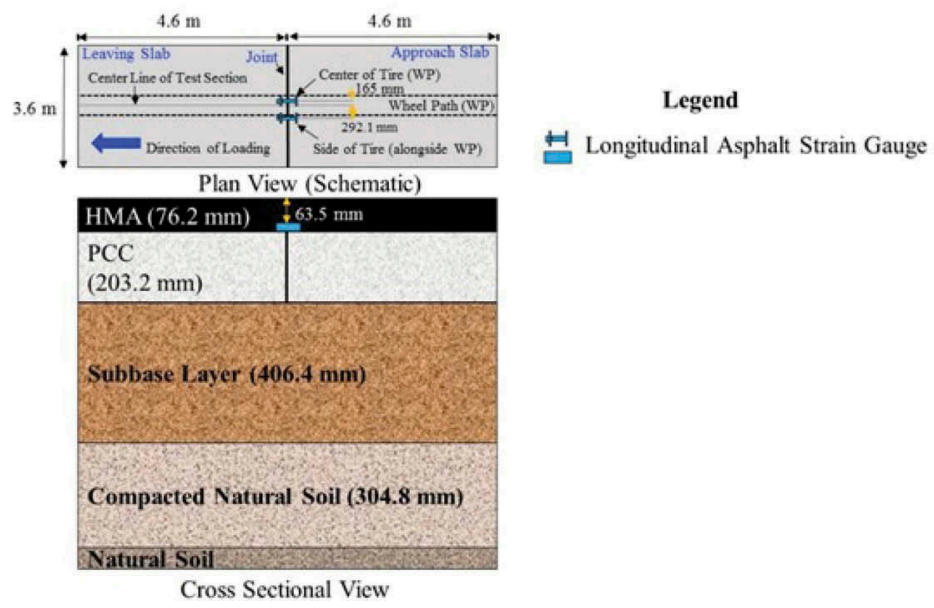

Figure 1. Pavement structure and instrumentation of test sections.

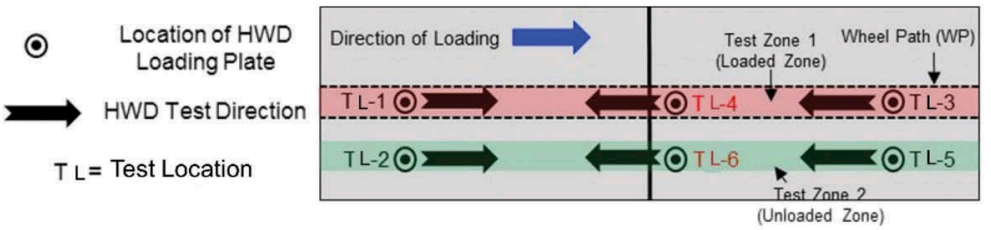

Figure 2. HWD test locations and test zones on each test section.

\subsection{Heavy vehicle simulator testing}

A heavy vehicle simulator (HVS) was used to apply full-scale loading on all three pavement sections evaluated in this study. Each test section was subjected to a $60-\mathrm{kN}$ load using a dualtire, single-axle wheel configuration. The pressure in both tires was maintained at $758.4 \mathrm{kPa}$ during loading. A total of 200,000 loading passes were applied on each test section at an $8 \mathrm{~km} / \mathrm{h}$, loading rate. Data from the embedded strain gauges was collected as HVS loading progressed on the test sections. A data acquisition system was used to collect strain measurements from the gauges during each load application. Strain data was collected at a frequency of 2,000 data points per second. The frequency at which strain measurements were recorded varied based on the stage of APT. Strain data was recorded: every 100 passes between HVS passes 1 and 1000, every 500 passes between HVS passes 1000 and 10,000, every 1000 passes 
between HVS passes 10,000 and 20,000, every 22,500 passes between HVS passes 20,000 and 50,000 , every 10,000 passes between HVS passes 50,000 and 100,000, and every 20,000 between HVS passes 100,000 and 200,000. The measurement of strain data during APT was important because it allowed for the degree of damage accumulation in each HMA overlay to be determined. The measured strain data also facilitated test sections performance comparison. This was essential in order to verify the overall effectiveness of the Outer-Area method in assessing the relative change in structural capacity of the full-scale section due to APT.

\section{OVERVIEW OF ANALYSIS PROCEDURES}

\subsection{Outer-area method}

The Outer-Area method was adopted in this study to analyze the measured deflections and draw conclusions about the structural capacity of the test sections. This method relies on the computation of a deflection basin curvature index (i.e., the Outer-AREA parameter) that is used together with a composite modulus $\left(\mathrm{E}_{\mathrm{o}}\right)$ index to forward calculate an approximate modulus for the upper, bound layer of a composite pavement system known as the effective stiffness index $\left(\mathrm{E}_{\mathrm{s}}\right)$ (Smith et al. 2017). The composite modulus represents an overall modulus for the entire pavement system beneath the loading plate while the Outer-AREA parameter represents a normalized area with respect to the measured deflection basin. Additionally, the Outer-AREA parameter ignores the deflections obtained directly under the applied load. Thus, the Outer-AREA parameter compensates for the magnitude of the imposed HWD load and to minimize the compression effect in the HMA layer (Smith et al. 2017).

The Outer-AREA parameter is a deflection basin shape factor that is related to the ratio between pavement stiffness and the underlying subgrade stiffness. It is strongly influenced by the thickness of a pavement structure and the stiffness of the materials that make up the structure. However, the parameter is inversely related to the mid-depth temperature of the asphalt layer within a pavement system. Therefore, temperature corrections are typically performed on the pavement deflection data in order to minimize the effect of temperature on the Outer-Area parameter (Smith et al. 2017). The effective stiffness index is determined by using Equations 1 to 4.

$$
\begin{gathered}
\mathrm{E} 0=\frac{\left(1.5 * \mathrm{a} * \sigma_{0}\right)}{\mathrm{D}_{0}} \\
\text { Outer }- \text { Area }=6\left(1+2\left(\frac{\mathrm{D} 3}{\mathrm{D} 2}\right)+2\left(\frac{\mathrm{D} 4}{\mathrm{D} 2}\right)+2\left(\frac{\mathrm{D} 5}{\mathrm{D} 2}\right)+2\left(\frac{\mathrm{D} 6}{\mathrm{D} 2}\right)+2\left(\frac{\mathrm{D} 7}{\mathrm{D} 2}\right)\right) \\
\mathrm{AF}=\left(\frac{\mathrm{k}_{2}-1}{\mathrm{k}_{2}-\left(\frac{\text { Outer-AREA }}{\mathrm{k}_{1}}\right)}\right)^{2} \\
\mathrm{Es}=\mathrm{Eo} * \mathrm{AF} * \mathrm{k}_{3}\left(\frac{1}{\mathrm{AF}}-1\right)
\end{gathered}
$$

Where: - $\left(\mathrm{E}_{0}\right)$ Composite modulus of pavement

- $\left(\mathrm{E}_{\mathrm{s}}\right)$ Effective stiffness index

- (a) radius of HWD plate

- $\left(\sigma_{0}\right)$ Peak pressure of HWD impact load under plate

- $\left(D_{0}\right)$ Peak center HWD deflection

- $\left(\mathrm{D}_{2}, \mathrm{D}_{3}, \mathrm{D}_{4}, \mathrm{D}_{5}, \mathrm{D}_{6}, \mathrm{D}_{7}\right)$ Measured pavement deflections at geophones

- (AF) Outer-Area factor

- $(\mathrm{k} 1)=11.037$ (Outer-AREA when upper layer stiffness equal that of lower layers)

- $(\mathrm{k} 2)=3.262$ (maximum possible improvement in Outer-AREA $(36 / 11.037)$ )

- (k3) Thickness of upper layer/load plate diameter 


\subsection{APT strain data analysis procedure}

The strain data collected from the embedded strain gauges in the full-scale, test sections were analyzed using the strain data analysis procedure developed by Francois et al. (2019). The strain data analysis procedure consists of four steps which, are illustrated in Figure 3. The first step of the strain data analysis procedure, entails converting the voltage signal recorded by the embedded, strain gauges into actual strain measure ements using calibration factors provided by the manufacturer. This step also involves filtering the strain time history response pulse using a 25-data point, moving average to reduce the number of data points required to accurately capture the strain response at a particular HVS pass.

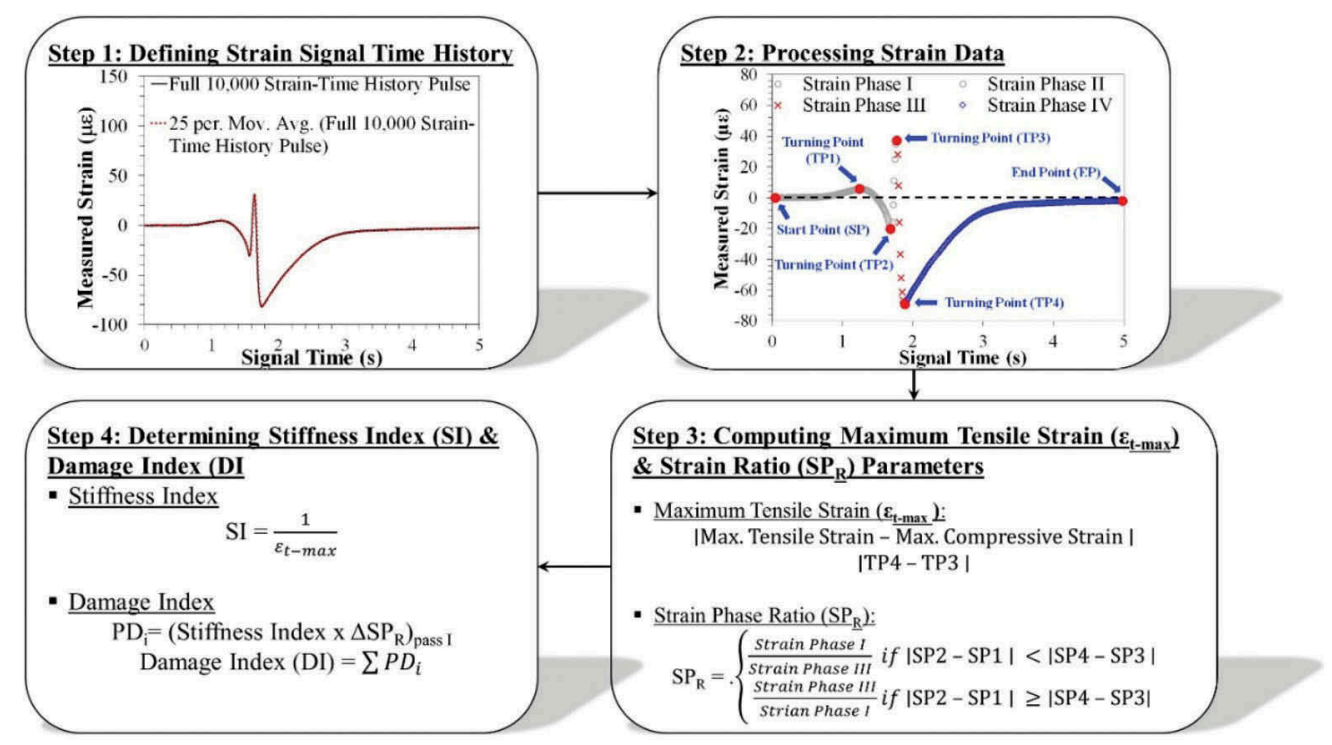

Figure 3. Summary of strain data analysis procedure developed by Francois et al. (2019).

The second step of the procedure involves identifying the critical points on the strain time history response pulse and defining the four phases of this pulse. Strain Phase I reflects the initial compressive strain the overlay experiences at the joint when the load approaches the strain gauge from the approach slab. Strain Phase II captures the tensile strain the HMA overlay experiences when the load was directly on top of the joint. Strain Phase III represents the compressive strain the overlay experiences as the load departs from the joint. Strain Phase IV highlights the gradual increase in strain when the HVS wheel load no longer directly impacts joint (or slab) deflection (Francois et al. 2019). The third step involves computing the maximum tensile strain $\left(\varepsilon_{t}-\max \right)$ and strain phase ratio $\left(\mathrm{SP}_{\mathrm{R}}\right)$ parameters based on the strain phases defined in Step 2. The fourth and final step of the strain analysis procedure entails determining the damage index (DI) (Figure 3). The damage index is used to compare the relative damage accumulation in the HMA overlays due to APT.

\section{RESULTS AND DISCUSSION}

\subsection{Analysis of HWD test results}

Table 1 presents the Outer-Area parameters that were computed directly from measured pavement deflections at the joint: within the HVS wheel path (TL-4 in Figure 2) and outside the 
Table 1. Outer-Area values computed at joint in test sections.

\begin{tabular}{llllr}
\hline & & \multicolumn{2}{l}{ Outer-Area Parameter } & \\
\cline { 3 - 4 } Test Section & $\begin{array}{l}\text { HWD Test } \\
\text { Location }\end{array}$ & Before HVS Testing & $\begin{array}{l}\text { After HVS } \\
\text { Testing }\end{array}$ & $\begin{array}{l}\text { Percent } \\
\text { Difference } \\
(\%)\end{array}$ \\
\hline Test Section 1 & TL-4 & 37.0 & 34.6 & 6.7 \\
(SMA) & TL-6 & 37.0 & 36.3 & 1.9 \\
Test Section 2 & TL-4 & 39.8 & 31.2 & 24.2 \\
(NJHPTO) & TL-6 & 40.8 & 38.2 & 6.5 \\
Test Section 3 & TL-4 & 40.4 & 26.1 & 43.0 \\
(9.5-ME \& BRIC) & TL-6 & 41.6 & 31.1 & 28.9 \\
Test Section 4 & TL-4 & 34.4 & 30.0 & 13.7 \\
(SMA \& BRIC) & TL-6 & 33.5 & 31.7 & 5.5 \\
Test Section 5 & TL-4 & 30.1 & 25.7 & 15.7 \\
(NJHPTO \& BRIC) & TL-6 & 30.5 & 29.0 & 5.0 \\
\hline
\end{tabular}

HVS wheel path (TL-6 in Figure 2). The results in Table 1 indicate that Section 3 had the highest Outer Area values before HVS loading followed by Sections 2, 1, 4, and 5, respectively. These results implied that the bound layers of the composite pavement in Section 3 had the highest stiffness of all test sections while the bound layers of Section 5 had the lowest stiffness. This is because higher Outer-AREA values typically reflect higher pavement stiffness. Based on the Outer-Area values computed for TL-4 in each test section, it can be inferred that Section 3 underwent the largest reduction in stiffness due to HVS loading followed by Sections $2,5,4$, and 1 , respectively. These results suggested that more damage accumulation may have occurred in the bound layers of Section 3 during APT while the bound layers in Section 1 may have experienced the least damage accumulation of all test sections.

Table 2 presents the effective stiffness index values that were obtained for all five test sections at the joint in the loaded and unloaded zone of each test section (i. e., HWD test locations TL-4 and TL-6 in Figure 2). These effective stiffness index values are the only ones presented because they quantify the overall stiffness of the composite pavement sections at the joint: where the most critical responses to loading occur. Since TL4 represented the HWD test location in the loaded zone and TL- 6 represented the HWD locations in the unloaded zone, the change in structural capacity of the test sections at the joint due to loading can be compared. The reduction in effective stiffness at TL-4 was generally larger than the effective stiffness reduction seen at TL-6. This trend was expected because TL-4 was located $38.1 \mathrm{~mm}$ from the joint in wheel path of the HVS while TL-6 was located $38.1 \mathrm{~mm}$ from the joint in the region not loaded by the HVS. Therefore the decrease in structural capacity captured at TL-4 was expected to be more significant than that captured at TL-6. With respect to the relative change in structural capacity of the test sections after HVS loading, it can be observed that Section 3 experienced the largest reduction in effective stiffness followed by Section 1, Section 2, Section 4, and Section 5, respectively. These results suggested that Section 3 experienced the most deterioration (i.e., damage accumulation) during HVS testing while Section 5 experienced the least deterioration (i.e. reduction in stiffness during APT.

\subsection{Analysis of APT test results}

The $\varepsilon_{\mathrm{t}}$-max was computed from all the strain-time history response pulses recorded in the five full-scale sections evaluated in this study. These results are illustrated in Figure 4a. The computed $\varepsilon_{\mathrm{t}}$-max values in all five sections increased (i.e., followed a logarithmic growth trend) as loading passes increased. This trend was expected because the increase in applied loading passes typically amounts to an increase in permanent strain (or damage) within the pavement sections. In addition, given the constant loading 
applied on top of all five pavement sections (i.e., $(60-\mathrm{kN})$ ), the rate of damage accumulation in each section can be compared at a particular loading pass. Based on this fact, the results indicated that the $9.5 \mathrm{ME} \&$ BRIC overlay experienced the most damage due to APT while 4.75-NJHPTO overlay underwent the least damage due to loading. This is because the rate of increase in $\varepsilon_{\mathrm{t}}$-max in Section 3 were largest followed by Sections 1 , 5,4 , and 2 NJHPTO respectively.

Figure $4 \mathrm{~b}$ Shows the Damage Index values obtained for each test section after each recorded loading pass. The damage index generally increased with loading passes as expected. However, the DI increased at different rates for the different HMA (or sections). By comparing the accumulated damage after applying a certain number of loading passes (for example 160,000 loading passes), it can be observed that Section 4 had the highest rate of accumulated damage followed by Section 5, Section 3, Section 2, and Section 1, respectively.

Table 2. Effective stiffness index computed at joint in test sections.

\begin{tabular}{lllll}
\hline \multirow{2}{*}{ Test Section } & & \multicolumn{2}{l}{ Effective Stiffness Index (Es) } & \\
\cline { 3 - 4 } & $\begin{array}{l}\text { HWD Test } \\
\text { Location }\end{array}$ & $\begin{array}{l}\text { Before HVSj } \\
\text { Testing }\end{array}$ & $\begin{array}{l}\text { After HVS } \\
\text { Testing }\end{array}$ & $\begin{array}{l}\text { Percent } \\
\text { Difference (\%) }\end{array}$ \\
\hline Test Section 1 (SMA) & TL-4 & 125,850 & 19,690 & 84.0 \\
Test Section 2 (NJHPTO) & TL-6 & 23350 & 16362 & 30.0 \\
& TL-4 & 73,095 & 15,991 & 78.1 \\
Test Section 3 (9.5-ME \& BRIC) & TL-6 & 60,981 & 19,169 & 68.5 \\
& TL-4 & 64,436 & 1,226 & 98.0 \\
Test Section 4 (SMA \& BRIC) & TL-6 & 21,679 & 6,933 & 68.0 \\
Test Section 5 (4.75-NJHPTO \& & TL-4 & 10,636 & 2,933 & 72.5 \\
BRIC) & TL-6 & 8,652 & 4,219 & 51.2 \\
& TL-4 & 7,477 & 4,364 & 41.6 \\
& TL-6 & 7,721 & 2,834 & 63.3 \\
\hline
\end{tabular}

\section{SUMMARY AND CONCLUSIONS}

The goal of this study was to evaluate the overall accuracy of the Outer-Area method in assessing the structural capacity of full-scale, composite pavement sections that are subjected to APT. Heavy weight deflectometer and accelerated pavement testing results obtained from five field sections that contained specialty New Jersey overlays were for this assessment. Based on the analyzed APT and HWD results, the following conclusions were drawn:

- Analyzed HWD results showed that Section 3 experienced the largest reduction in effective stiffness followed by Section 1, Section 2, Section 4, and Section 5, respectively.

- Analyzed strain data from full-scale testing indicated that Section 4 had the highest rate of accumulated damage after APT followed by Section 5, Section 3, Section 2, and Section 1, respectively.

- Reduction in structural capacity ranking obtained from the Outer-Area method did not coincide with damage accumulation ranking obtained from the Francois et al. 2009 strain data analysis procedure.

- Outer-Area method may not be able to accurately quantify the damage full-scale composite pavements experience due to APT. However, further research is required as this may appear to be the case due to the limited scope of this study. 


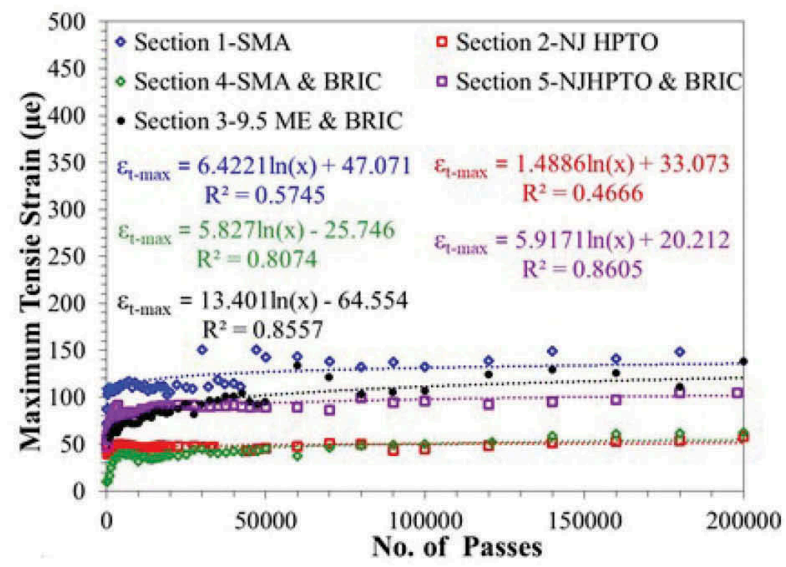

(a)

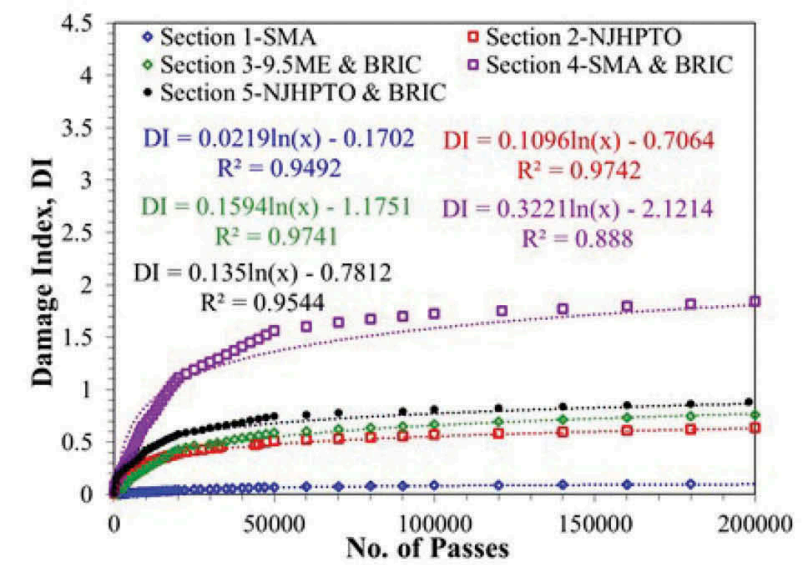

(b)

Figure 4. Summary of strain data analysis procedure developed by Francois et al. 2009.

\section{REFERENCES}

Francois, A. Ali, A. and Mehta, Y. 2019. A proposed approach for processing and analyzing strain data collected in full-scale accelerated pavement testing. Proceedings of 5th Conference on Smart Monitoring Assessment and Rehabilitation of Civil Structures, Potsdam, Germany.

Maestas, J. and Mamlouk, M. 1992. Comparison of Pavement Deflection Analysis Methods Using Overlay Design. Transportation Research Record: Journal of the Transportation Research Board, Vol. 1377, pp.17-21.

Mehta, Y. and Roque, R. 2003. Evaluation of FWD Data for Determination of Layer Moduli of Pavements. Journal of Materials in Civil Engineering, Vol. 15, No. 1, pp. 25-31.

Smith, K. Bruinsma, J. Wade, M. Chatti, K. Vandenbossche, J. and Thomas, H. 2017.Using Falling Weight Deflectometer Data with Mechanistic-Empirical Design and Analysis, Volume I: Final Report. Federal Highway Administration, Washington D.C., FHWA-HRT-16-009. 